\title{
Albumin-binding Prodrugs of Camptothecin and Doxorubicin with an Ala-Leu-Ala- Leu-Linker that are Cleaved by Cathepsin B: Synthesis and Antitumor Efficacy
}

\author{
Björn Schmid ${ }^{1 \#}$, Da-Eun Chung ${ }^{1 \#}$, André Warnecke $^{1}$, Iduna Fichtner ${ }^{2}$, Felix Kratz $^{1 *}$ \\ ${ }^{1}$ Tumor Biology Center, Breisacher Strasse 117, 79106 Freiburg, Germany. \\ ${ }^{2}$ Max-Delbrück Centrum, Robert-Rössle-Strasse 10, 13122 Berlin, Germany.
}

\section{SUPPORTING INFORMATION}

Chromatography. HPLC for the determination of the purity of the CPT prodrug was performed on a Waters system (pump: Waters 616, detector: Waters 996 photodiode array detector; controller: Waters 600S; autosampler: Waters 717; software: Empower 2002); chromatographic conditions for the CPT prodrug: Nucleosil ${ }^{\circledR} \mathrm{C} 18$ column $(100-5,250 \times 4 \mathrm{~mm})$ from Macherey-Nagel; flow: $1.2 \mathrm{~mL} / \mathrm{min}$; mobile phase A: $30 \% \mathrm{MeCN}, 70 \%$ demin. $\mathrm{H}_{2} \mathrm{O}$, $0.1 \%$ TFA; mobile phase $\mathrm{B}: 50 \% \mathrm{MeCN}, 50 \%$ demin. $\mathrm{H}_{2} \mathrm{O}, 0.1 \%$ TFA; gradient: 0-20 min $0 \%$ to $100 \%$ mobile phase $\mathrm{B} ; 20-30 \min 100 \%$ mobile phase $\mathrm{B}$ isocrat.; $30-40$ min $0 \%$ to $100 \%$ mobile phase A; injection volume: $50 \mu \mathrm{L}$; detection at $\lambda=280 \mathrm{~nm}$ and $\lambda=370 \mathrm{~nm}$. Chromatographic conditions for the DOXO prodrug: Waters Symmetry ${ }^{\circledR}$ C18 column (300-5, $250 \times 4.6 \mathrm{~mm}$ ) with pre-column; chromatographic conditions: flow: $1.2-1.8 \mathrm{~mL} / \mathrm{min}$; mobile

\footnotetext{
${ }^{\#}$ Both authors contributed equally to this work.

${ }^{*}$ To whom correspondence should be addressed: Dr. Felix Kratz, Tumor Biology Center, Department of Medical Oncology, Clinical Research, Breisacher Strasse 117, D-79106 Freiburg, Federal Republic of Germany; Tel.: +49-761-2062930; Fax.: +49-761-2062905; e-mail: felix @tumorbio.uni-freiburg.de.
} 
phase A: $70 \% \mathrm{MeCN}, 30 \% 20 \mathrm{mM}$ potassium phosphate (pH 7.0); mobile phase B: $27.5 \%$ MeCN, $72.5 \% 20 \mathrm{mM}$ potassium phosphate (pH 7.0); gradient: 0-26 min $100 \%$ mobile phase $\mathrm{B} ; 26-41 \mathrm{~min} 0 \%$ to $100 \%$ mobile phase $\mathrm{A} ; 41-50$ min $100 \%$ mobile phase A isocrat.; 50-60 min $0 \%$ to $100 \%$ mobile phase $\mathrm{B}$; injection volume: $50 \mu \mathrm{L}$; detection at $\lambda=$ $280 \mathrm{~nm}$ and $\lambda=495 \mathrm{~nm}$.

HPLC for incubation and stability studies with the CPT prodrug was performed with the above-mentioned Waters system; column: Waters Symmetry ${ }^{\circledR}$ C18 $(300-5,250 \times 4.6 \mathrm{~mm})$ with pre-column; chromatographic conditions: flow: $1.2 \mathrm{~mL} / \mathrm{min}$; mobile phase A: $30 \% \mathrm{MeCN}$, $70 \% 20 \mathrm{mM}$ triethylammonium acetate (TEAA) buffer (pH 7.0), mobile phase B: $70 \%$ MeCN, $30 \% 20$ mM TEAA buffer (pH 7.0), gradient: 0-26 min $100 \%$ mobile phase A isocrat.; $26-41 \min 0 \%$ to $100 \%$ mobile phase $\mathrm{B} ; 41-50$ min $100 \%$ mobile phase B isocrat.; 50-60 min $0 \%$ to $100 \%$ mobile phase A; injection volume: $50 \mu \mathrm{L}$, detection at $\lambda=280 \mathrm{~nm}$ and $\lambda=370 \mathrm{~nm}$. The HPLC experiments in which the cysteine-34 position of MSA was blocked with an excess of EMC prior to incubation with prodrug 1 were carried out with the same Waters system and the same chromatographic conditions but by use of a $20 \mathrm{mM}$ sodium phosphate buffer ( $\mathrm{pH}$ 3.0) instead of a 20 mM TEAA buffer ( $\mathrm{pH}$ 7.0). For the DOXO prodrug a Biorad System (BioLogic Duo-Flow), connected to a Merck F-1050 Fluorescence Spectrophotometer (EX. $490 \mathrm{~nm}$, EM. $540 \mathrm{~nm}$ ) and a Lambda 1000 visible detector from Bischoff (at $\lambda=495 \mathrm{~nm}$ ), was used; UV-detection at $254 \mathrm{~nm}$; column: Waters, $300 \AA$, Symmetry C18 (4.6 x $250 \mathrm{~mm})$ with pre-column.

Chromatographic conditions for incubation studies with mouse blood plasma and the DOXO prodrug: flow: $1.2 \mathrm{~mL} / \mathrm{min}$; mobile phase A: $30 \% \mathrm{MeCN}, 70 \% 20 \mathrm{mM}$ potassium phosphate (pH 7.0); mobile phase B: $70 \% \mathrm{MeCN}, 30 \% 20 \mathrm{mM}$ potassium phosphate (pH 7.0); gradient: 0-25 $\min 100 \%$ mobile phase $\mathrm{A} ; 25-40 \min 0 \%$ to $100 \%$ to mobile phase $\mathrm{B} ; 40$ 50 min $100 \%$ mobile phase B isocrat.; $50-60 \min 0 \%$ to $100 \%$ to mobile phase A; injection volume: $50 \mu \mathrm{L}$. 
Chromatographic conditions for incubation and cleavage studies with the DOXO prodrug and the cleavage product H-Leu-Ala-Leu-DOXO: flow: $1.2 \mathrm{~mL} / \mathrm{min}$; mobile phase A: $35 \%$ MeCN, $65 \% 4$ mM sodium phosphate buffer (pH 3.0); mobile phase B: $70 \%$ MeCN, $30 \% 4$ $\mathrm{mM}$ sodium phosphate buffer ( $\mathrm{pH} 3.0$ ); gradient: $0-25$ min $100 \%$ mobile phase A; 25-40 $\min 0 \%$ to $100 \%$ to mobile phase $\mathrm{B} ; 40-50 \min 100 \%$ mobile phase $\mathrm{B}$ isocrat.; $50-60 \min 0$ $\%$ to $100 \%$ to mobile phase A; injection volume: $50 \mu \mathrm{L}$.

Figure S1: Curves depicting body weight change of HT-29 xenografted nude mice under therapy with camptothecin and $\mathbf{1}$.

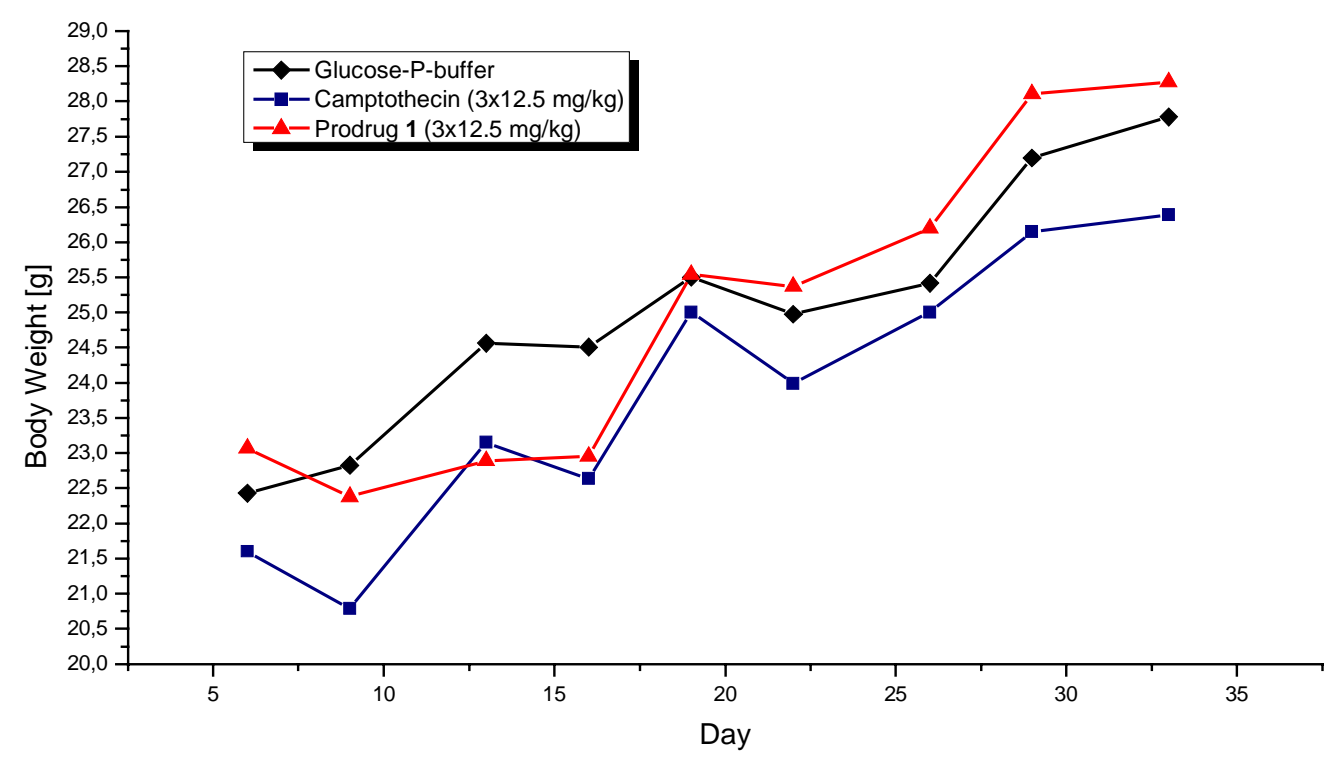


Figure S2: Curves depicting body weight change of M-3366 xenografted nude mice under therapy with doxorubicin and 2 .

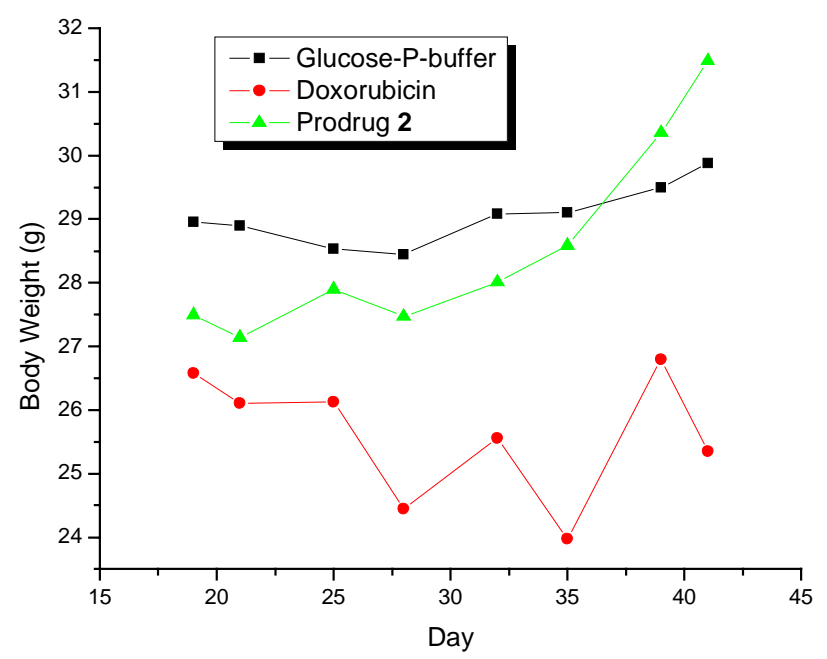

Figure S3: Chromatograms of HSA-1 $(250 \mu \mathrm{M})$ depicting the buffer stability for TEAA buffer $\mathrm{pH} 5.0$ and $\mathrm{pH} 7.4$ after $24 \mathrm{~h}$.

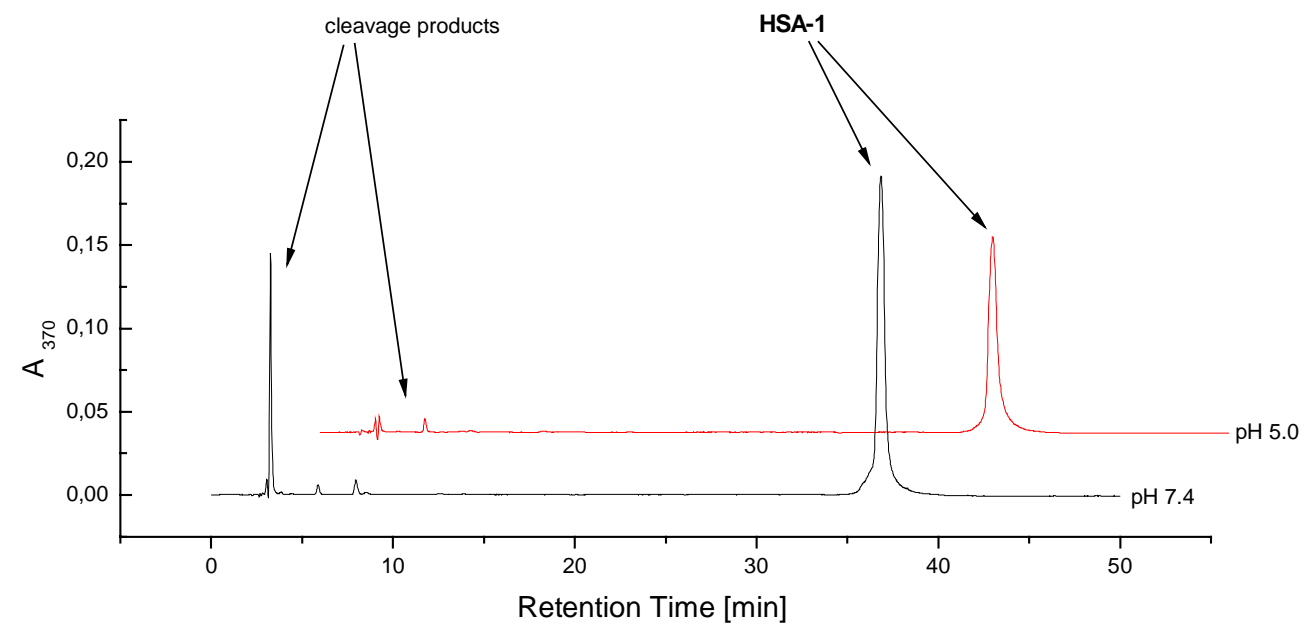


Figure S4: Mass spectra of the cleavage products of HSA-1 after incubation with HT-29 colon tumor tissue homogenate determined by LC-MS spectrometry.

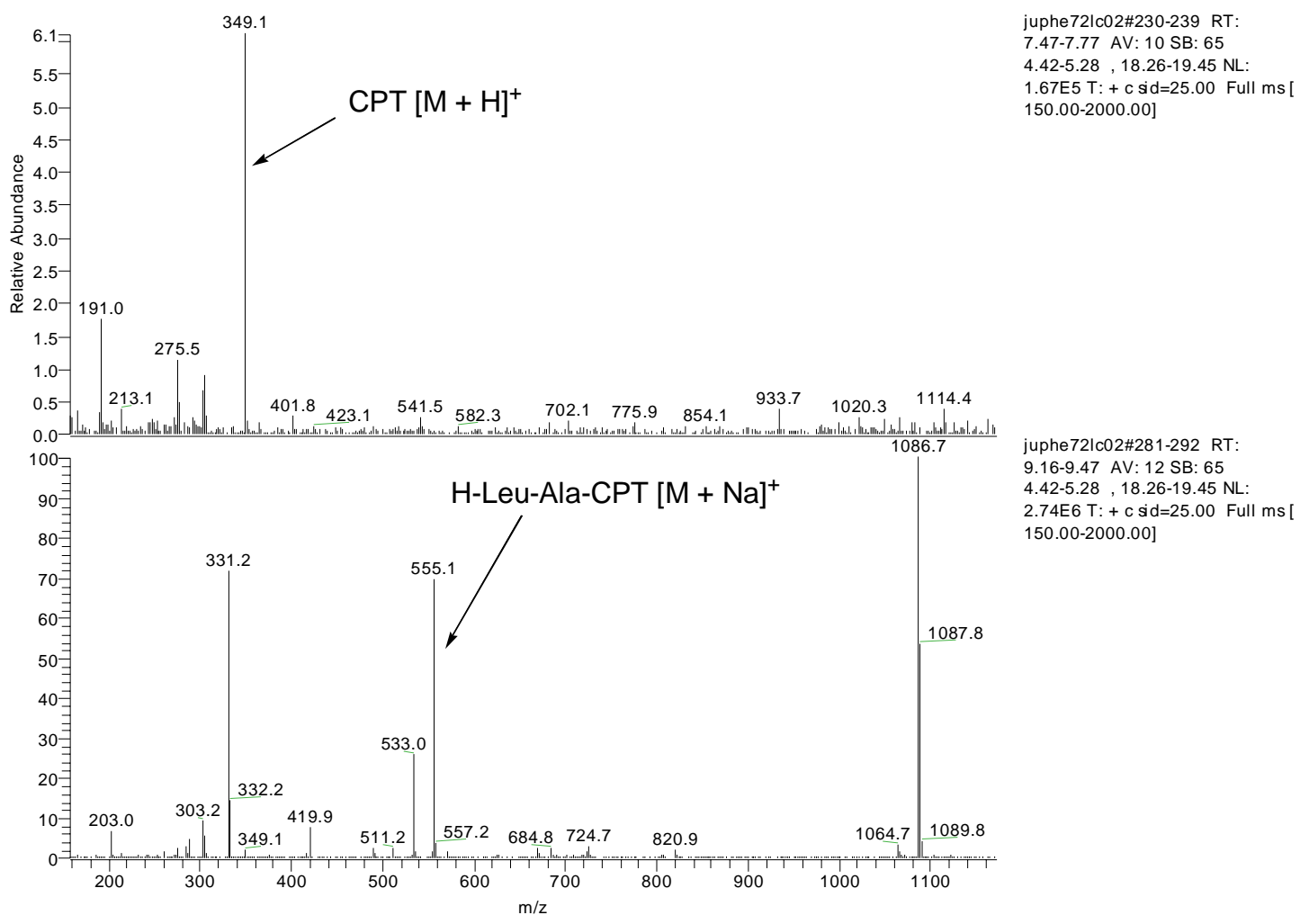



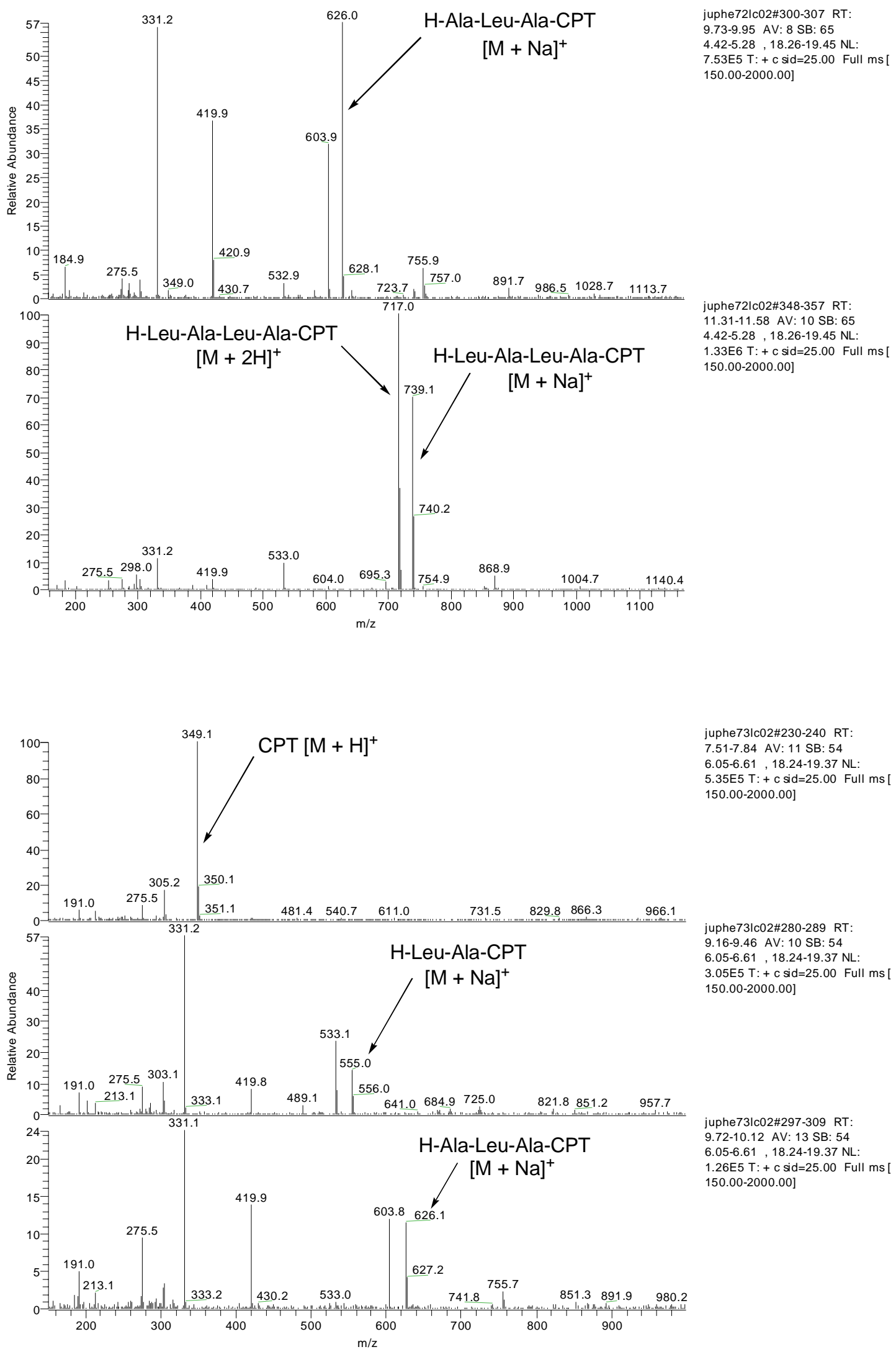

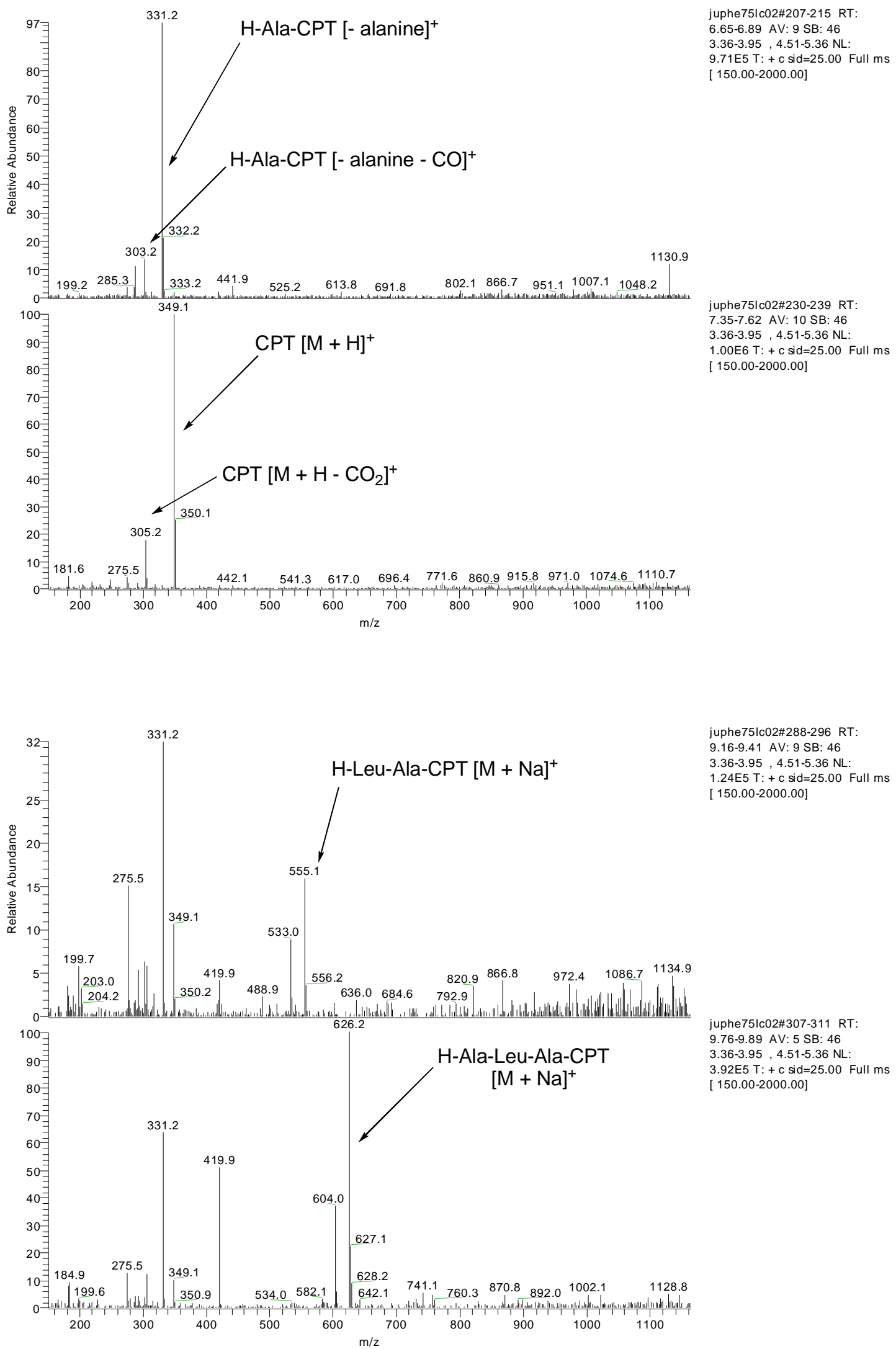
Figure S5: Mass spectrum of the cleavage product [H-Leu-Ala-Leu-DOXO, $\left.840.8 \mathrm{M}^{+}\right]$and its $\mathrm{Na}^{+}$adduct [H-Leu-Ala-Leu-DOXO, $\left.863.1[\mathrm{M}+\mathrm{Na}]^{+}\right]$.

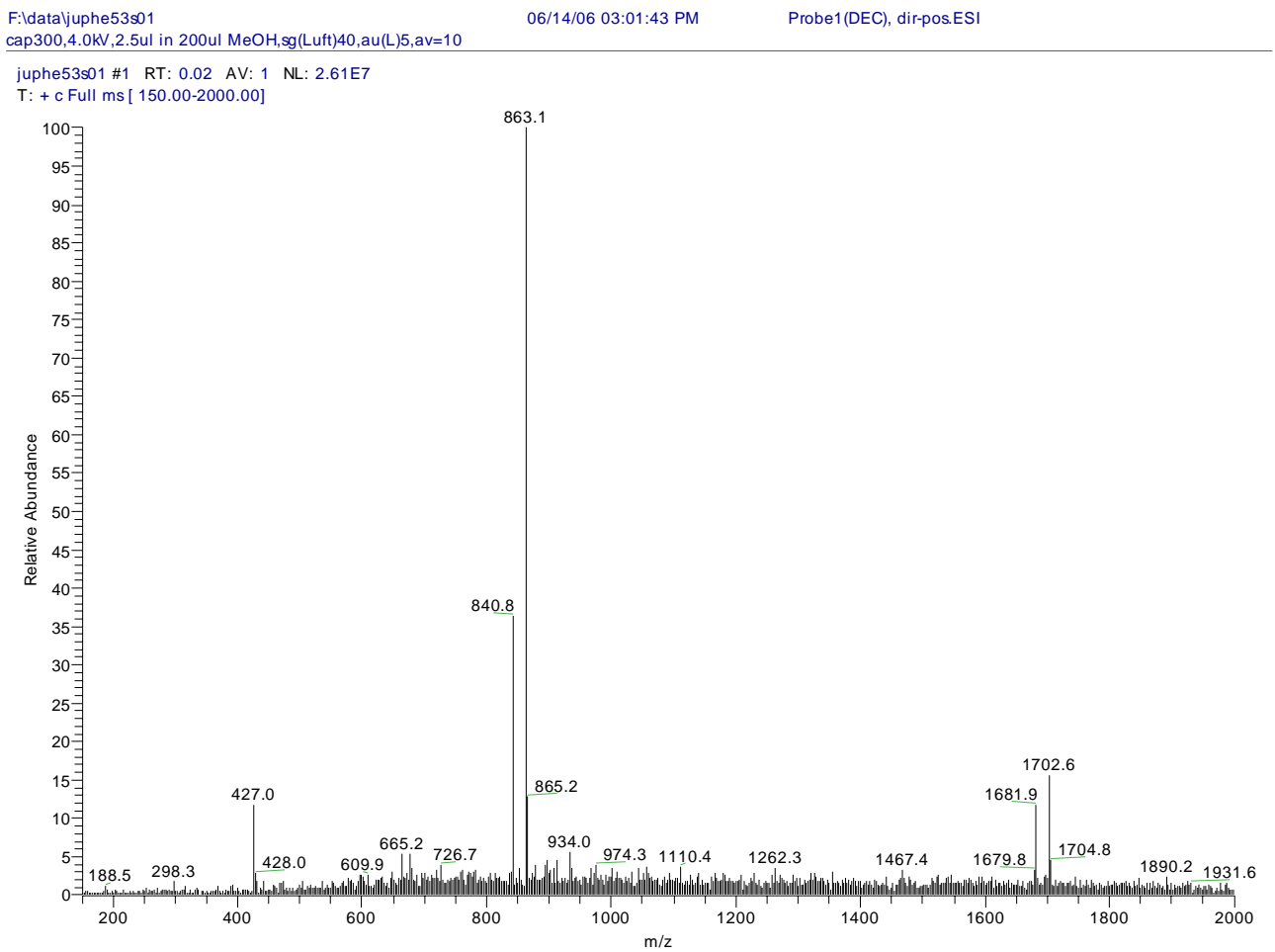


Figure S6: Mass spectra of the cleavage products of HSA-2 after incubation with M-3366 mamma tumor tissue homogenate at $\mathrm{pH} 7.4$ determined by LC-MS spectrometry.

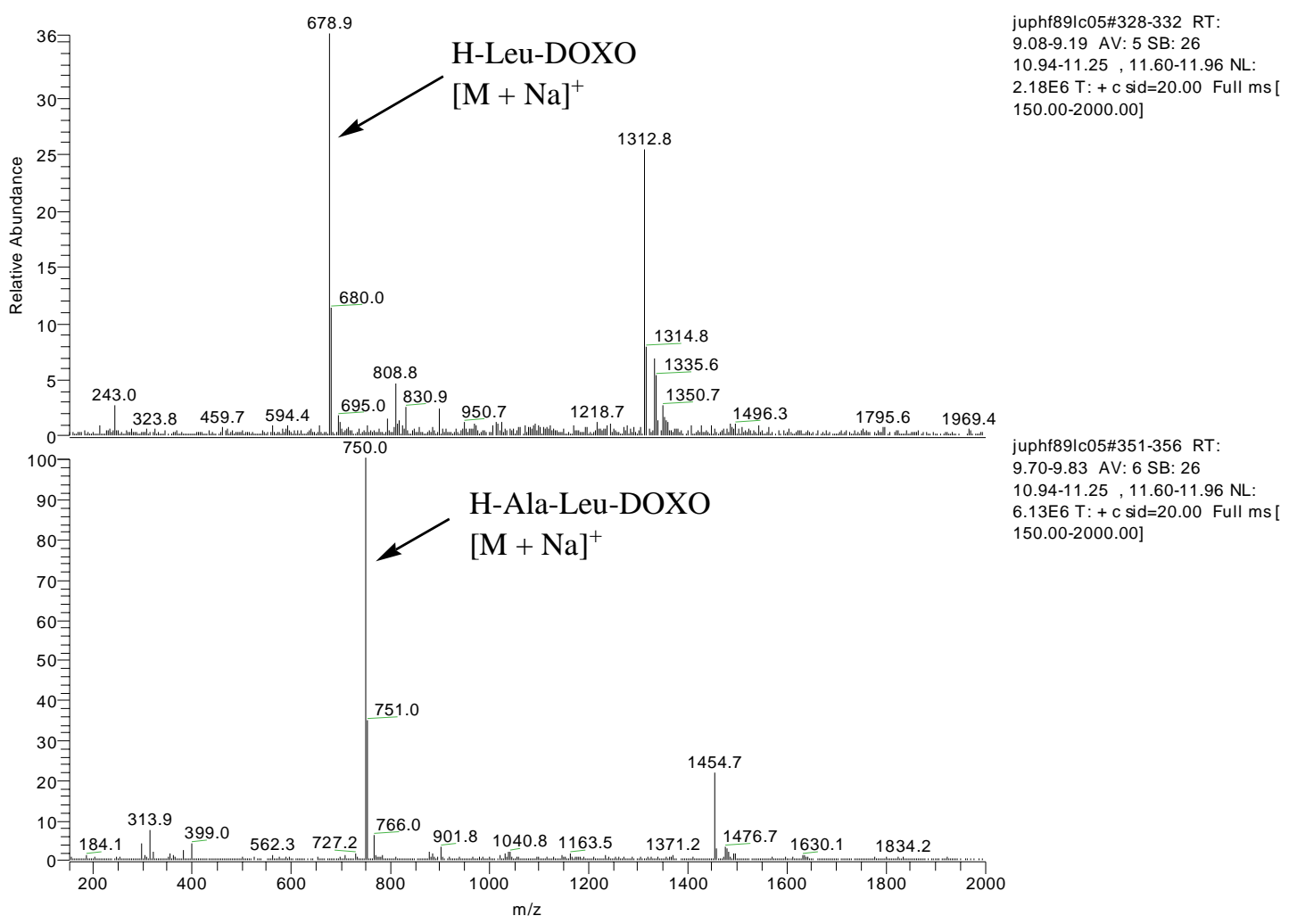


F:Idataljuphf89lc05 11/13/06 04:31:02 PM Dec-013.4

LC-MS-pos.ESI,Jupiter-C4,300A/5u,150x2mm,col-T:40' ,350ul/min 10\%B-50\%B(15-20), ESI: 4.0kV,cap300,sg 40,au(Luft)10,scid 20V

juphf89Ic05 \#416-417 RT: 11.49-11.52 AV: 2 SB: 7 11.35-11.44, 11.57-11.63 NL: 8.58E5

$\mathrm{T}:+\mathrm{c}$ sid $=20.00$ Full ms [ 150.00-2000.00]

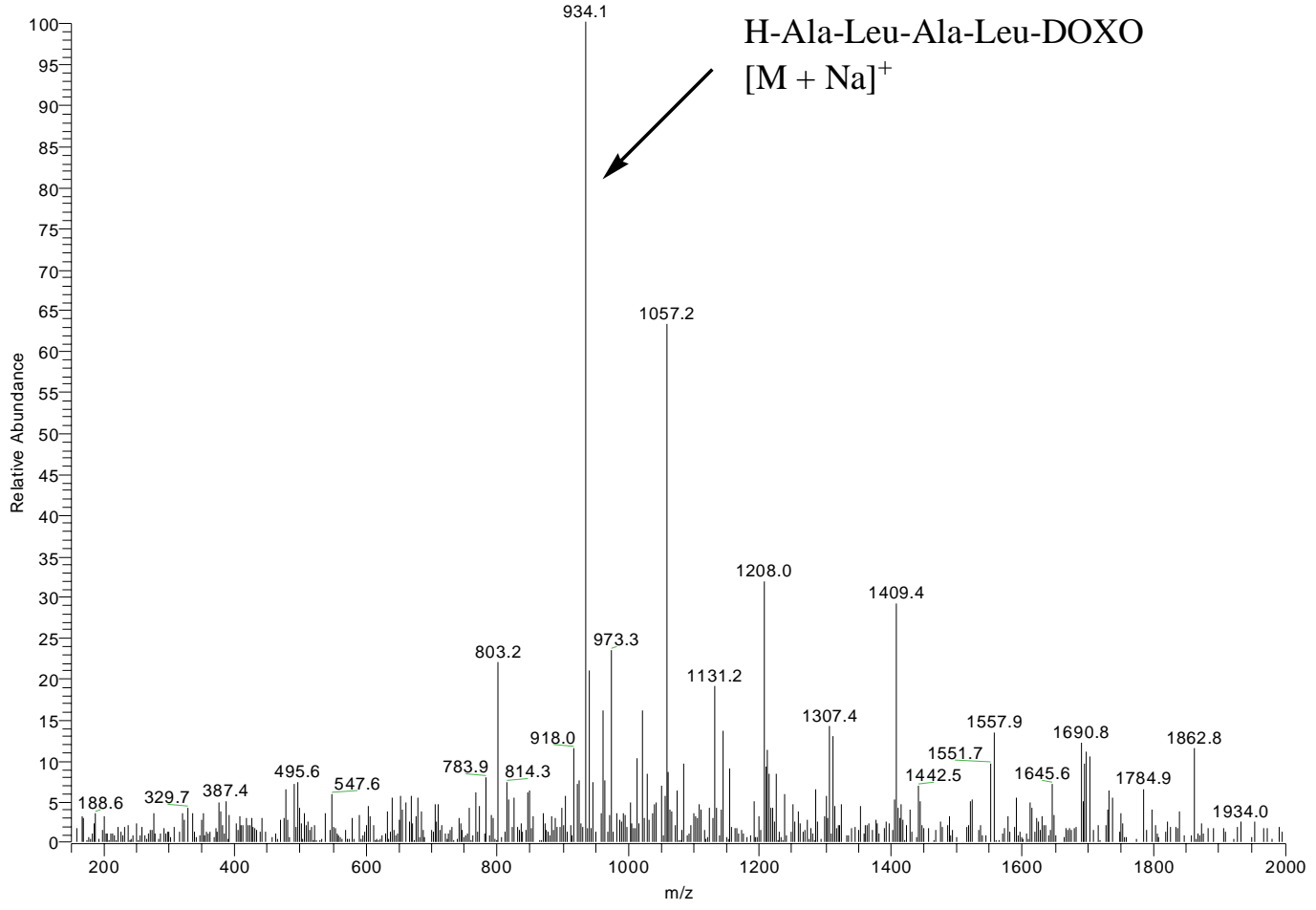

